\title{
Weather sensitivity associated with quality of life in patients with fibromyalgia
}

\author{
Kazuhiro Hayashi ${ }^{1}$, Kenji Miki ${ }^{2,3^{*}}$, Noriyuki Hayashi ${ }^{4}$, Ryota Hashimoto ${ }^{5}$ and Masao Yukioka ${ }^{3,6}$
}

\begin{abstract}
Background: Fibromyalgia is characterized by chronic widespread pain, and more than half of patients with fibromyalgia report that weather-related variables aggravate their symptoms. However, the differences in actual symptoms have not been measured between those with and without weather sensitivity. The present study aimed to investigate whether weather sensitivity associated with the minimal clinically important difference values of quality of life in patients with fibromyalgia, between those with and without weather sensitivity.

Methods: Sixty-four consecutive outpatients with fibromyalgia on their first visit to our tertiary center were included. Weather sensitivity was measured using self-perceived symptoms. Pain intensity was measured using the 0-10 Numerical Rating Scale (NRS). Quality of life was measured using the Euro Quality of life-5 Dimensions-3 level (EQ-5D-3L) scale. The variables were subjected to univariable and multivariable analysis using the EQ-5D-3L scale.

Results: The mean age of the patients was 50 years. Forty-eight patients (75\%) were women. The mean EQ-5D-3L score was 0.55 . Thirty-seven patients (58\%) reported weather sensitivity. In univariable analysis, the welfare recipient, weather sensitivity, and NRS values were associated with EQ-5D-3L scale scores. In multivariable analysis, NRS value and weather sensitivity were independently associated with EQ-5D-3L scale scores. The NRS and EQ-5D-3L scale scores were significantly worse in those with weather sensitivity than those without weather sensitivity. The difference in NRS values was less than 1.5 points between groups. The differences in EQ-5D-3L scale scores were 0.16 points between groups.
\end{abstract}

Conclusions: Weather sensitivity was significantly associated with quality of life in patients with fibromyalgia. There was an association with weather sensitivity and the minimal clinically important difference values of quality of life in patients with fibromyalgia. The presence of weather sensitivity could have a key role in the quality of life in patients with fibromyalgia.

Keywords: Fibromyalgia, Weather, Quality of life, Pain, Observation

\section{Background}

Fibromyalgia is a disease characterized by chronic widespread pain without a known cause or cure [1-4]. The prevalence of fibromyalgia is estimated to be approximately $2 \%$ in the general population [5-9]. The coexisting symptoms are sleep disturbance, fatigue, depression,

\footnotetext{
*Correspondence: kenji-miki@umin.ac.jp

${ }^{2}$ Center for pain management, Hayaishi Hospital, Osaka, Japan

${ }^{3}$ Faculty of Health Science, Osaka Yukioka College of Health Science, Osaka, Japan

Full list of author information is available at the end of the article
}

and anxiety; however, these are not universal [1-4]. Clinical care of patients with fibromyalgia is uncertain in many areas. The routine care in patients should include a comprehensive assessment of quality of life, and not only specific symptoms $[10,11]$. The Euro quality of life5 Dimensions (EQ-5D) scale is a generic patientreported quality of life measurement. The scale can be used for cost-effectiveness studies across diseases. It is a 5 -item questionnaire that after appropriate weighting results in a scale ranging from -0.11 to 1.00 . Fibromyalgia

(c) The Author(s). 2021 Open Access This article is licensed under a Creative Commons Attribution 4.0 International License, which permits use, sharing, adaptation, distribution and reproduction in any medium or format, as long as you give appropriate credit to the original author(s) and the source, provide a link to the Creative Commons licence, and indicate if changes were made. The images or other third party material in this article are included in the article's Creative Commons licence, unless indicated otherwise in a credit line to the material. If material is not included in the article's Creative Commons licence and your intended use is not permitted by statutory regulation or exceeds the permitted use, you will need to obtain permission directly from the copyright holder. To view a copy of this licence, visit http://creativecommons.org/licenses/by/4.0/. The Creative Commons Public Domain Dedication waiver (http://creativecommons.org/publicdomain/zero/1.0/) applies to the data made available in this article, unless otherwise stated in a credit line to the data. 
has a negative impact on quality of life, with an EQ-5D scale score of $0.45-0.61[12,13]$.

Potential factors that aggravate fibromyalgia symptoms are weather-related variables, physical activity, emotional distress, and sleep disturbance [14, 15]. Specifically, weather-related variables are one of the major aggravating factors [14-19]. Weather-related variables are measured using self-perceived symptoms or local weather situations [14-25]. In recent patient population studies, weather-related variables were significantly associated with pain in fibromyalgia; however, the associations were too minor to be of any clinical significance [20-25]. Thus, a recent study hypothesizes that the relation of weather-related variables may be clinically significant at the individual level [25]. More than half of the patients reported that weather sensitivity aggravates pain; however, the differences in actual symptoms have not been measured between those with and without weather sensitivity [14-19].

The present study aimed to investigate whether weather sensitivity associated with the minimal clinically important difference values of quality of life in patients with fibromyalgia, between those with and without weather sensitivity.

\section{Methods}

\section{Subjects}

All methods were carried out in accordance with relevant guidelines and regulations. This study was approved by the Ethics Committee of Hayaishi Hospital, and all study participants provided written informed consent. The sample size was calculated using the G*Power software (version 3.1.9.2; Franz Faul, Kiel University, Kiel, Germany). Based on an effect size of 0.3, [20-25] the minimum number of subjects was estimated to be 64 for an $\alpha$-level of 0.05 , and a power $(1-\beta)$ of 0.80 .

Data were retrospectively collected from medical records of consecutive outpatients with fibromyalgia during their first visit to our tertiary center. Inclusion criteria were: 1) age > 20 years; and 2) a diagnosis of fibromyalgia by a medical doctor, based on the American College of Rheumatology 2010 criteria $[1,26]$. The diagnostic criteria consist of the Widespread Pain Index and the Symptom Severity Scale. Exclusion criteria were cancer-related pain, neurological disease, evidence of bone fractures, recent surgery within the past 6 months, or poor Japanese language comprehension. A total of 64 patients with fibromyalgia were included (from February 2017 to June 2018) in the analysis.

\section{Measures}

Demographic data, including age, body mass index, sex, marital status, and welfare recipient were collected during the first visit to our tertiary center. Weather sensitivity, pain intensity, and quality of life were measured as described below.

Weather sensitivity was routinely taken for all patients in our institution. Weather sensitivity was measured using self-perceived symptoms [14-19]. Subjects were assigned into two categories, those "with weather sensitivity" and "without weather sensitivity", based on their "Yes" or "No" responses to single question: "Does change in weather affect your pain?" [14, 16].

Pain intensity was measured using the $0-10$ Numerical Rating Scale (NRS) [27]. The scale, ranging from 0 to 10, was obtained as an indicator of the average level of pain during the day. The scale labeled at the anchor points with 0 as "no pain" and 10 as "worst possible pain". The minimal clinically important difference was 2 points in chronic pain $[28,29]$.

Quality of life was measured using the Euro Quality of life-5 Dimensions-3 level (EQ-5D-3L) scale, a generic scale used worldwide that assesses health in five dimensions: mobility, self-care, usual activities, pain/discomfort, and anxiety/depression [10, 11]. Each domain was assessed by a single question with three possible responses: no problems, some problems, or serious health problems. The combination of all possible dimensions and levels results in 243 unique health states. It can be converted into EQ-5D-3L scale scores ranging from 0.111 to 1.000 . Negative scores represent health states considered worse than being dead, 0 represents being dead, and 1.00 represents a state of full health. The minimal clinically important difference was 0.08 points in chronic pain [28, 29].

\section{Statistical analysis}

All continuous data were expressed as means and standard deviations. The normality of the distribution was evaluated using the Shapiro-Wilk test for continuous variables. The correlation of EQ-5D-3L scale score with each variable was analyzed using the Pearson correlation coefficient test. The categorical variables included a dummy variable for the analysis. Multivariable analysis was used to investigate variables with $p<0.2$ in the univariable analysis. Four variables were analyzed in the multivariable analysis for EQ5D-3L scale score: marital status, welfare recipient, weather sensitivity, and the NRS values. Multicollinearity of the variables was also assessed (correlation coefficient $<0.9$ ).

All data were statistically analyzed using the SPSS $26.0 \mathrm{~J}$ program, and $P$ values $<0.05$ were considered significant.

\section{Results}

Patient characteristics are shown in Table 1 . The mean age of the patients was 50 years. Of the 64 patients, 48 
Table 1 Patient characteristics $(n=64)$

\begin{tabular}{ll}
\hline Age, $y$ & $50(16)$ \\
Body mass index, $\mathrm{kg} / \mathrm{m}^{2}$ & $22(4)$ \\
Women, $\mathrm{n}(\%)$ & $48(75 \%)$ \\
Married, $\mathrm{n}(\%)$ & $31(48 \%)$ \\
Welfare recipient, $\mathrm{n}(\%)$ & $9(14 \%)$ \\
Weather sensitivity, $\mathrm{n}(\%)$ & $37(58 \%)$ \\
NRS & $5.8(1.7)$ \\
EQ-5D-3L scale & $0.55(0.18)$
\end{tabular}

EQ-5D-3L Euro Quality of life-5 Dimensions-3 level, NRS Numerical Rating Scale Data from continuous variables are shown as mean (standard deviation). Data from categorical variables are shown as number (\%)

(75\%) were women. The number of patients with weather sensitivity was $37(58 \%)$. The mean NRS value was 5.8. The mean EQ-5D-3L score was 0.55 .

Correlations between the EQ-5D-3L scale scores and independent variables are shown in Table 2 . The welfare recipient, weather sensitivity, and NRS value were significantly associated with EQ-5D-3L scale scores in univariable analysis.

The results of multivariable analysis for the EQ-5D-3L scale scores are shown in Table 3. The EQ-5D-3L scale score was significantly associated with the NRS value and weather sensitivity in multivariable analysis. Multicollinearity was not observed for any of the independent variables tested in the analyses.

Table 4 and Fig. 1 show a comparison between those with and without weather sensitivity. The NRS values and EQ-5D-3L scale scores were significantly worse in those with weather sensitivity than those without weather sensitivity. The difference in NRS values was less than 1.5 points between groups. The differences in EQ-5D-3L scale scores were 0.16 points between groups.

Table 2 Correlation between EQ-5D-3L scale and the independent variables

\begin{tabular}{lll}
\hline & Correlation coefficient & $\boldsymbol{P}$ value \\
\hline Age & 0.083 & 0.512 \\
Women & -0.123 & 0.333 \\
Body mass index & -0.084 & 0.507 \\
Married & 0.224 & 0.076 \\
Welfare recipient & -0.313 & $0.012^{*}$ \\
Weather sensitivity & -0.438 & $<0.001^{*}$ \\
NRS & -0.522 & $<0.001^{*}$ \\
\hline
\end{tabular}

EQ-5D-3L Euro Quality of life-5 Dimensions-3 level, NRS Numerical Rating Scale These data were analyzed using the Pearson correlation coefficient test. The categorical variables included a dummy variable for analysis. The welfare recipient, weather sensitivity, and NRS value were significantly associated with EQ-5D-3L scale scores in the univariable analysis. *Significance level was set at $<5 \%$
Table 3 Multivariable analysis for EQ-5D-3L scale

\begin{tabular}{llllll}
\hline Independent Variables & $\mathbf{B}$ & $\mathbf{S E}$ & Beta & $\boldsymbol{P}$ value & $\mathbf{R}^{\mathbf{2}}$ \\
\hline NRS & -0.035 & 0.012 & -0.344 & $0.004^{*}$ & 0.349 \\
Weather sensitivity & -0.106 & 0.040 & -0.301 & $0.010^{*}$ & \\
Welfare recipient & & & & 0.065 & \\
Married & & & & 0.651 & \\
\hline B
\end{tabular}

$B$, nonstandard regression coefficient; Beta, standardized regression coefficient; EQ-5D-3L Euro Quality of life-5 Dimensions-3 level, NRS Numerical Rating Scale,

$R^{2}$ Multiple correlation coefficient adjusted for degrees of freedom, $S E$ Standard error

These data were analyzed using multivariable analysis. Multicollinearity of the variables was also assessed (correlation coefficient $<0.9$ ). EQ-5D-3L scale score was significantly associated with the NRS value and weather sensitivity in multivariable analysis. *Significance level was set at $<5 \%$

\section{Discussion}

The present study demonstrated that weather sensitivity was significantly associated with quality of life in patients with fibromyalgia. The findings suggested that the presence of weather sensitivity could have a key role in the quality of life in these patients.

Fibromyalgia induces pain and reduces the quality of life $[12,13]$. Previous patient population studies suggested that associations with weather-related variables and pain were too small to be clinically significant in patients with fibromyalgia [20-25]. The minimal clinically important difference for NRS value is 2 points in chronic pain $[28,29]$. The present study demonstrated that the difference in NRS values was less than 1.5 points between groups; this suggests that the association with weather sensitivity and pain was too small to be clinically significant, consistent with previous studies [20-25]. Meanwhile, the minimal clinically important difference for EQ-5D scale score is 0.08 points in chronic pain [28, 29]. The present study demonstrated that the differences in EQ-5D scale scores were 0.16 points between groups. The EQ-5D scale consists of mobility, self-care, activity, pain/discomfort, and anxiety/depression [10, 11]. Patients with fibromyalgia often suffer sleep disturbance, fatigue, cognitive impairment, depression and anxiety $[1-4,30]$. Fibromyalgia reduces functioning in physical, psychological, and social spheres, and also has a negative impact on personal relationships, work, daily activities, and mental health [30]. Cold season seems to be associated with increased depression, [31, 32] although sometimes limited [33]. The scores of Hospital Anxiety and Depression Scale-Depression subscale were significantly higher in patients with weather sensitivity than those without weather sensitivity (Supplement Fig. 1.). Meanwhile, the associations among weather sensitivity, seasonality and other symptoms have not been shown in fibromyalgia.

Many patients report that weather sensitivity aggravates pain, [14-19] consistent with the present study. Although the pathologic mechanism behind the association 
Table 4 Comparison between those with and without weather sensitivity

\begin{tabular}{llll}
\hline & $\begin{array}{l}\text { With weather } \\
\text { sensitivity }(\boldsymbol{n}=\mathbf{3 7})\end{array}$ & $\begin{array}{l}\text { Without weather } \\
\text { sensitivity }(\boldsymbol{n}=\mathbf{2 7})\end{array}$ & $\begin{array}{c}\boldsymbol{P} \text { value } \\
\text { Age, } \mathrm{y}\end{array}$ \\
Body mass index, $\mathrm{kg} / \mathrm{m}^{2}$ & $50(15)$ & $50(17)$ & 0.996 \\
Women, $\mathrm{n}(\%)$ & $23(4)$ & $22(4)$ & 0.201 \\
Married, $\mathrm{n}(\%)$ & $29(78 \%)$ & $19(70 \%)$ & 0.563 \\
Welfare recipient, $\mathrm{n}(\%)$ & $16(43 \%)$ & $15(56 \%)$ & 0.448 \\
NRS & $5(14 \%)$ & $4(15 \%)$ & $>0.999$ \\
EQ-5D-3L scale & $6.3(1.7)$ & $5.0(1.5)$ & $0.001^{*}$ \\
\hline
\end{tabular}

EQ-5D-3L Euro Quality of life-5 Dimensions-3 level, NRS Numerical Rating Scale

These data were analyzed using $\mathrm{t}$ test or chi-square test. Data from continuous variables are shown as mean (standard deviation). Data from categorical variables are shown as number (\%). The NRS value and EQ-5D-3L scale score were significantly worse in those with weather sensitivity than those without weather sensitivity. * Significance level was set at $<5 \%$

is largely unknown, lowering barometric pressure induces neuronal activation in the superior vestibular nucleus in animals [34]. In a human study, air pressure is suggested to be associated with rheumatoid arthritis synovitis [35]. Meanwhile, the severity of symptom is associated with a belief about weather than in actual local weather situations [19]. Negative self-assessment has an important role in psychological disturbances, which are known to be associated with pain perception [36-38]. Psychological status may also partially mediate the association between weather sensitivity and pain; however, evidence on this is scarce $[23,24]$.

Interventions in combination and organization would benefit fibromyalgia [2-4]. Treatment plans should incorporate self-management techniques, goal-setting, and healthy lifestyle habits, acknowledging psychological distress when present. The effects of their treatment approaches on aggravating factors have not been shown.

There are several limitations to the present study. First, weather sensitivity was measured using only self-

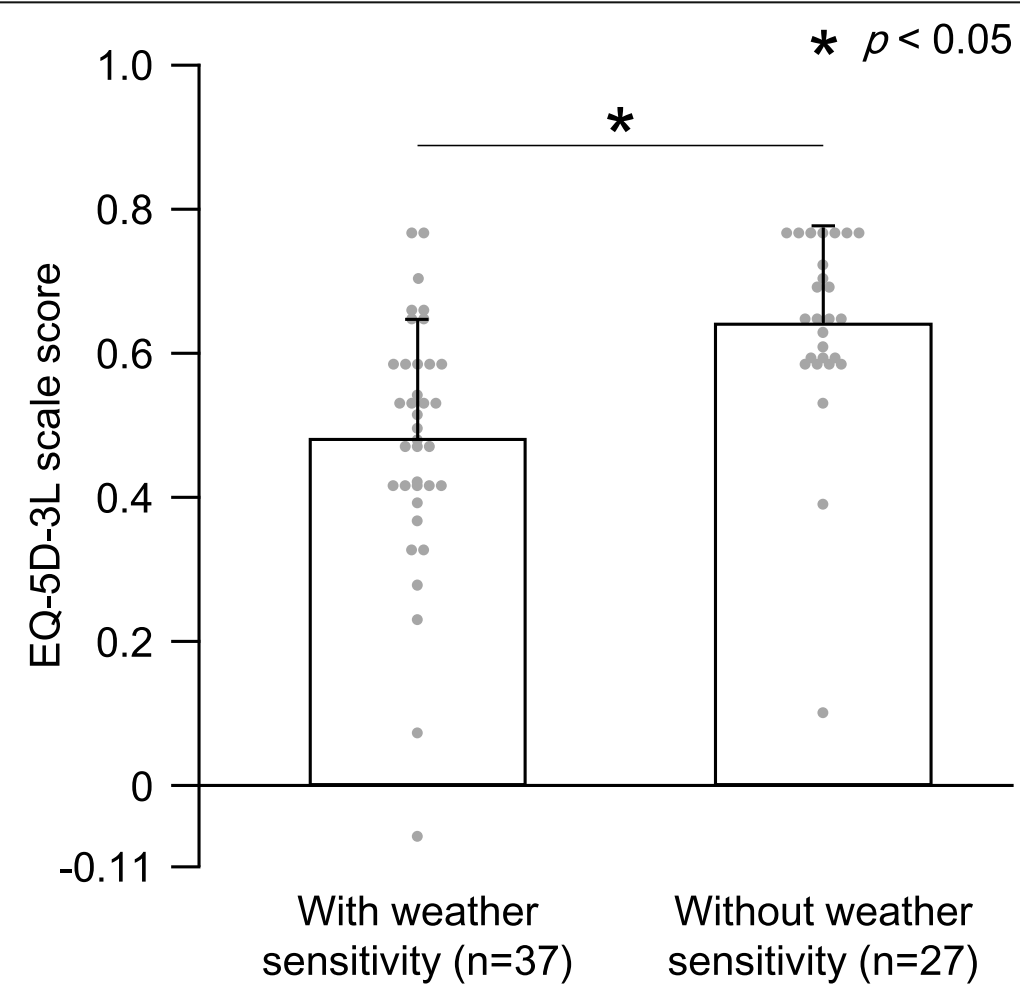

Fig. 1 Difference of EQ-5D-3L scale between those with and without weather sensitivity. Values are means of the EQ-5D-3L scale score, and the error bar shows standard deviations. Dot plots show individual patient data. The EQ-5D-3L scale scores in those with weather sensitivity were significantly worse than those without weather sensitivity. * Significance level was set at < 5\%.EQ-5D-3L, Euro Quality of life-5 Dimensions-3 level 
perceived symptoms using a binary scale, not a rating scale or actual local weather situations. Although the weather sensitivity using a binary scale is shown in one of the major aggravating factor in patients with fibromyalgia, $[14,16]$ there is a possibility of misclassification error. Second, the present study included only a small number of patients from a single medical center; our observations must therefore be interpreted with caution.

\section{Conclusions}

Weather sensitivity, followed by pain intensity, was significantly associated with quality of life. There was an association with weather sensitivity and the minimal clinically important difference values of quality of life in patients with fibromyalgia. This suggests that weather sensitivity could play a key role in the quality of life in patients with fibromyalgia. Ascertaining the presence of weather sensitivity has the potential to be useful in estimating the level of suffering experienced by patients with fibromyalgia.

\section{Abbreviations}

NRS: Numerical Rating Scale; EQ-5D-3L: Euro Quality of life-5 Dimensions-3 level

\section{Supplementary Information}

The online version contains supplementary material available at https://doi. org/10.1186/s41927-021-00185-4

Additional file 1: Supplement Fig. 1. Difference of HADS-Depression subscale between those with and without weather sensitivity. Values are means of the HADS-Depression subscale score, and the error bar shows standard deviations $(n=51)$. The HADS-Depression subscale scores in those with weather sensitivity were significantly worse than those without weather sensitivity. ${ }^{*}$ Significance level was set at $<5 \%$. HADS, Hospital Anxiety and Depression Scale.

\section{Acknowledgements}

The authors sincerely thank all patients, collaborating physicians, and other medical staff for their important contributions to this study.

\section{Authors' contributions}

$\mathrm{KH}$ and $\mathrm{KM}$ designed the study and wrote the main manuscript text. $\mathrm{NH}, \mathrm{RH}$ and MY prepared and supervised analyses. All named authors meet the International Committee of Medical Journal Editors (ICMJE) criteria for authorship for this article, take responsibility for the integrity of the work as a whole, and have given their approval for this version to be published.

\section{Funding}

There was no funding received for this study.

\section{Availability of data and materials}

The datasets used and/or analysed during the current study are available from the corresponding author on reasonable request.

\section{Declarations}

Ethics approval and consent to participate

The Research Ethics Committee of Hayaishi Hospital approved this study. All patients have provided informed consent for the present study.

Consent for publication

Not applicable.

\section{Competing interests}

The authors declare that they have no competing interests.

\section{Author details}

${ }^{1}$ Multidisciplinary Pain Center, Aichi Medical University, Nagakute, Japan. ${ }^{2}$ Center for pain management, Hayaishi Hospital, Osaka, Japan. ${ }^{3}$ Faculty of Health Science, Osaka Yukioka College of Health Science, Osaka, Japan. ${ }^{4}$ Department of Psychiatry, Yukioka Hospital, Osaka, Japan. ${ }^{5}$ Department of Pathology of Mental Diseases, National Institute of Mental Health, National Center of Neurology and Psychiatry, Kodaira, Japan. ${ }^{6}$ Department Rheumatology, Yukioka Hospital, Osaka, Japan.

Received: 11 December 2020 Accepted: 25 February 2021

Published online: 10 May 2021

\section{References}

1. Wolfe F, Clauw DJ, Fitzcharles MA, Goldenberg DL, Katz RS, Mease P, et al. The American College of Rheumatology preliminary diagnostic criteria for fibromyalgia and measurement of symptom severity. Arthritis Care Res (Hoboken). 2010;62:600-10.

2. Fitzcharles MA, Ste-Marie PA, Goldenberg DL, Pereira JX, Abbey S, Choinière M, et al. Canadian Pain Society and Canadian Rheumatology Association recommendations for rational care of persons with fibromyalgia: a summary report. J Rheumatol. 2013;40:1388-93.

3. Macfarlane GJ, Kronisch C, Dean LE, Atzeni F, Häuser W, Fluß E, et al. EULAR revised recommendations for the management of fibromyalgia. Ann Rheum Dis. 2017;76:318-28

4. Japanese College of Fibromyalgia Investigation. Fibromyalgia practical guideline 2017. Tokyo: Nihon-lji-Shinpousha; 2017. (In Japanese)

5. Wolfe F, Ross K, Anderson J, Russell IJ, Hebert L. The prevalence and characteristics of fibromyalgia in the general population. Arthritis Rheum. 1995;38:19-28.

6. Lawrence RC, Felson DT, Helmick CG, Arnold LM, Choi H, Deyo RA, et al. Estimates of the prevalence of arthritis and other rheumatic conditions in the United States part II. Arthritis Rheum. 2008;58:26-35.

7. Queiroz LP. Worldwide epidemiology of fibromyalgia. Curr Pain Headache Rep. 2013;17:356.

8. Toda K. The prevalence of fibromyalgia in Japanese workers. Scand J Rheumatol. 2007;36:140-4

9. Nakamura I, Nishioka K, Usui C, Osada K, Ichibayashi H, Ishida M, et al. An epidemiologic internet survey of fibromyalgia and chronic pain in Japan. Arthritis Care Res (Hoboken). 2014;66:1093-101.

10. EuroQol Group. EuroQol--a new facility for the measurement of healthrelated quality of life. Health Policy. 1990;16:199-208.

11. Tsuchiya A, Ikeda S, Ikegami N, Nishimura S, Sakai I, Fukuda T, et al. Estimating an EQ-5D population value set: the case of Japan. Health Econ. 2002;11:341-53.

12. Wolfe F, Michaud K, Li T, Katz RS. EQ-5D and SF-36 quality of life measures in systemic lupus erythematosus: comparisons with rheumatoid arthritis, noninflammatory rheumatic disorders, and fibromyalgia. J Rheumatol. 2010; 37:296-304.

13. Salaffi F, Di Carlo M, Carotti M, Farah S, Ciapetti A, Gutierrez M. The impact of different rheumatic diseases on health-related quality of life: a comparison with a selected sample of healthy individuals using SF-36 questionnaire, EQ-5D and SF-6D utility values. Acta Biomed. 2019;89:541-57.

14. Ruiz Moral R, Muñoz Alamo M, Pérula de Torres L, Aguayo Galeote M. Biopsychosocial features of patients with widespread chronic musculoskeletal pain in family medicine clinics. Fam Pract. 1997;14:242-8.

15. Bennett RM, Jones J, Turk DC, Russell IJ, Matallana L. An internet survey of 2,596 people with fibromyalgia. BMC Musculoskelet Disord. 2007;8:27.

16. Yunus M, Masi AT, Calabro JJ, Miller KA, Feigenbaum SL. Primary fibromyalgia (fibrositis): clinical study of 50 patients with matched normal controls. Semin Arthritis Rheum. 1981;11:151-71.

17. Guedj D, Weinberger A. Effect of weather conditions on rheumatic patients. Ann Rheum Dis. 1990:49:158-9.

18. de Blécourt AC, Knipping AA, de Voogd N, van Rijswijk MH. Weather conditions and complaints in fibromyalgia. J Rheumatol. 1993;20:1932-4.

19. Hagglund KJ, Deuser WE, Buckelew SP, Hewett J, Kay DR. Weather, beliefs about weather, and disease severity among patients with fibromyalgia. Arthritis Care Res. 1994;7:130-5. 
20. Fors EA, Sexton $\mathrm{H}$. Weather and the pain in fibromyalgia: are they related? Ann Rheum Dis. 2002;61:247-50.

21. Strusberg I, Mendelberg RC, Serra HA, Strusberg AM. Influence of weather conditions on rheumatic pain. J Rheumatol. 2002:29:335-8.

22. Macfarlane TV, McBeth J, Jones GT, Nicholl B, Macfarlane GJ. Whether the weather influences pain? Results from the EpiFunD study in north West England. Rheumatology (Oxford). 2010;49:1513-20.

23. Bossema ER, van Middendorp H, Jacobs JW, Bijlsma JW, Geenen R. Influence of weather on daily symptoms of pain and fatigue in female patients with fibromyalgia: a multilevel regression analysis. Arthritis Care Res (Hoboken). 2013;65:1019-25.

24. Smedslund G, Eide H, Kristjansdottir ÓB, Nes AA, Sexton H, Fors EA. Do weather changes influence pain levels in women with fibromyalgia, and can psychosocial variables moderate these influences? Int J Biometeorol. 2014;58:1451-7.

25. Fagerlund AJ, Iversen M, Ekeland A, Moen CM, Aslaksen PM. Blame it on the weather? The association between pain in fibromyalgia, relative humidity, temperature and barometric pressure. PLoS One. 2019;14:e0216902.

26. Usui C, Hatta K, Aratani S, Yagishita N, Nishioka K, Kanazawa T, et al. The Japanese version of the 2010 American College of Rheumatology Preliminary Diagnostic Criteria for fibromyalgia and the fibromyalgia symptom scale: reliability and validity. Mod Rheumatol. 2012;22:40-4.

27. Gewandter JS, Dworkin RH, Turk DC, Farrar JT, Fillingim RB, Gilron I, et al. Research design considerations for chronic pain prevention clinical trials: IMMPACT recommendations. Pain. 2015;156:1 184-97.

28. Salaffi F, Stancati A, Silvestri CA, Ciapetti A, Grassi W. Minimal clinically important changes in chronic musculoskeletal pain intensity measured on a numerical rating scale. Eur J Pain. 2004;8:283-91.

29. Suzuki H, Aono S, Inoue S, Imajo Y, Nishida N, Funaba M, et al. Clinically significant changes in pain along the pain intensity numerical rating scale in patients with chronic low back pain. PLoS One. 2020;15:e229228.

30. Galvez-Sánchez CM, Duschek S, Reyes Del Paso GA. Psychological impact of fibromyalgia: current perspectives. Psychol Res Behav Manag. 2019;12:117-27.

31. Stordal E, Morken G, Mykletun A, Neckelmann D, Dahl AA. Monthly variation in prevalence rates of comorbid depression and anxiety in the general population at 63-65 degrees north: the HUNT study. J Affect Disord. 2008; 106:273-8.

32. Oyane NM, Bjelland I, Pallesen S, Holsten F, Bjorvatn B. Seasonality is associated with anxiety and depression: the Hordaland health study. J Affect Disord. 2008;105:147-55.

33. de Graaf R, van Dorsselaer S, ten Have M, Schoemaker C, Vollebergh WA Seasonal variations in mental disorders in the general population of a country with a maritime climate: findings from the Netherlands mental health survey and incidence study. Am J Epidemiol. 2005;162:654-61.

34. Sato J, Inagaki H, Kusui M, Yokosuka M, Ushida T. Lowering barometric pressure induces neuronal activation in the superior vestibular nucleus in mice. PLoS One. 2019;14:e0211297.

35. Terao C, Hashimoto M, Furu M, Nakabo S, Ohmura K, Nakashima R, et al. Inverse association between air pressure and rheumatoid arthritis synovitis. PLoS One. 2014;9:e85376.

36. Edwards RR, Fillingim RB. Self-reported pain sensitivity: lack of correlation with pain threshold and tolerance. Eur J Pain. 2007;11:594-8.

37. Ruscheweyh R, Marziniak M, Stumpenhorst F, Reinholz J, Knecht S. Pain sensitivity can be assessed by self-rating: development and validation of the pain sensitivity questionnaire. Pain. 2009;146:65-74.

38. Ikemoto T, Hayashi K, Arai YC, Nishihara M, Inoue S, Inoue M, et al. The relationship between musculoskeletal pain and picky eating: the role of negative self-labeling. Pain Ther. 2019;8:101-10.

\section{Publisher's Note}

Springer Nature remains neutral with regard to jurisdictional claims in published maps and institutional affiliations.

\section{Ready to submit your research? Choose BMC and benefit from:}

- fast, convenient online submission

- thorough peer review by experienced researchers in your field

- rapid publication on acceptance

- support for research data, including large and complex data types

- gold Open Access which fosters wider collaboration and increased citations

- maximum visibility for your research: over $100 \mathrm{M}$ website views per year

At $\mathrm{BMC}$, research is always in progress.

Learn more biomedcentral.com/submissions 